\title{
Clinical characteristics and diabetes complications among Moroccan diabetic pilgrims
}

\begin{abstract}
Hajj (Pilgrimage) is one of the five pillars of Islam. During Hajj, the person's life routine changes, weather, diet and habits are different; therefore diabetes that depends on a stable routine would predictably be significantly affected. The aim of this study is to highlight the epidemiology, clinical data of diabetic Moroccan Pilgrims. We performed a prospective study conducted over a period of 50 days from the 07 august 2017 until 11 September 2017, based on questionnaire. The total number of patients was 80 (40 men and 40 women), all of them belong to type 2 diabetes mellitus. The mean of age was $62.85 \mathrm{y}(+/-8,9 \mathrm{SD})$. The mean of duration of diabetes was $9.37 \mathrm{ans}$ $(+/-7.3 \mathrm{SD})$.The mean of Random Plasma Glucose was $1.58 \mathrm{~g} / 1$ (SD+/-0.4). In our study, $11.3 \%$ of patients had diabetic nephropathy, $13.8 \%$ had diabetic neuropathy and $1.3 \%$ had heart disease. We admitted 4 patients (5\%) for DKA. Poor diabetes control in pilgrims with diabetes predisposes to morbidity and increases risk of acute complications. Patients with diabetes insist on performing Hajj, thereby creating a medical challenge for themselves and their health care providers.
\end{abstract}

Volume 6 Issue 5 - 2018

\author{
Abainou Lahoussaine, Hamza Eljadi, Sanae \\ Elhadri, Hicham Baizri \\ Department of Endocrinology, Diabetology and Metabolic \\ Diseases, Military Hospital Avicenna, Morocco
}

Correspondence: Abainou Lahoussaine, Doctor, Kadi Ayyad, Department of Endocrinology, Diabetology and Metabolic Diseases, Military Hospital Avicenna, Marrakech, Morocco, Tel +212678747303, Email abainoulhoussaine@gmail.com

Received: September 02, 2018 | Published: October 04, 2018

Keywords: diabetes, pilgrims, clinical data

\section{Introduction}

Haj is one of the five cardinal components of Islam commonly known as the five pillars of Islam. Approximately two million Muslims perform it each year. It is a compulsory pilgrimage for all those who are able to bear its financial and physical burdens once in their lives. The rituals of Hajj take place approximately over one week from the 8th to 13th day of the month of Dhul Hijjah.

For Hajjis (i.e. the people performing Hajj) this is a time of extraordinary physical and mental stress. In the context of diabetes, this means that Hajjis are at increased risk of both hyper and hypo glycaemia and increased morbidity and mortality from diabetes itself as well as inter current illness.

Diabetes currently affects 425 million adults worldwide, with most cases being type 2 diabetes. The number of patients with diabetes in Muslim populations (Middle East and Africa) is predicted to more than double by 2040. A similar increase is expected in South East Asia, another area where Islam predominates. ${ }^{2}$

In Morocco, more than 2 million people aged 25 and over are diabetic, $50 \%$ of whom are women (reported by the Ministry of Health, November 2017).

As for fasting during Ramadan, the majority of pilgrims wish to accomplish Hajj even to the detriment of their health as is the case of diabetics; there is an immediate requirement for practical guidance for the many Muslims with diabetes planning to perform Hajj over the coming years.

Poor diabetes control in pilgrims with diabetes predisposes to morbidity and increases risk of acute complications. The aim of this study is to highlight the clinical characteristics and diabetes complications of Moroccan diabetic Pilgrims.

Literature search has shown that there are few and old data available on the status of diabetic pilgrims. To our knowledge, this is the first study performed on Moroccan pilgrims. It was conducted in the City of Al-Medina Al-Munawarah.

\section{Methods}

\section{Study design}

We performed a prospective study conducted over a period of 50 days from the 07 august 2017 until 11 September 2017, based on questionnaire. All diabetics pilgrims were attended in our Consultation Center for Moroccan pilgrims installed in the City of Al-Medina AlMunawarah and whose goal was to follow the Moroccan pilgrims and provide them with the necessary care (Figure 1). The questionnaire included several schemas; the first part focused on demographic information including gender, age or date of birth and reported preexisting illnesses.

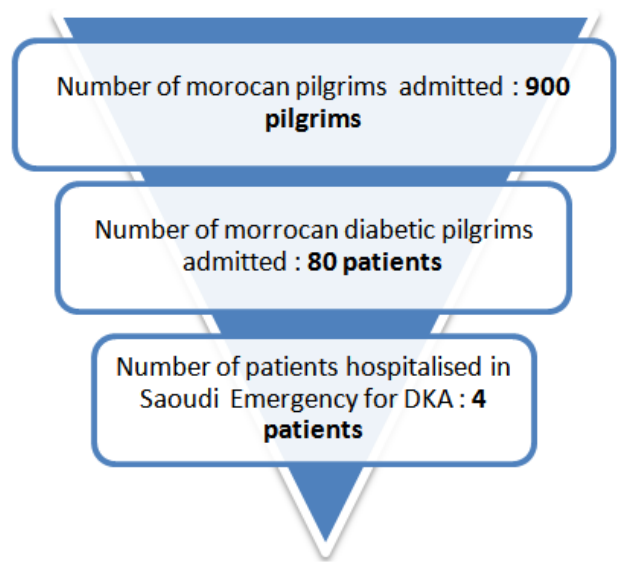

Figure I Flow-Shart of our study. 
The second part, included information on the type and duration of diabetes, medications and known complications. The last part was destined to clinical findings (weight, height, blood pressure (BP) and random plasma glucose levels (RPG))

A formal ethics approach was not necessary because the study involved only collection of anonymous data.

\section{Statistical methods}

All analyses were performed using SPSS for Windows (version 8.0; SPSS, Chicago, IL). The significance of univariate differences was assessed by $\chi 2$ and Student's t tests.

\section{Results}

The total number of patients who visited the diabetic clinic was 80 ; all of theme belongs to type 2 diabetes mellitus. The sex ratio was $1 / 1$. Demographic features of our population are shown in Table 1.

Table I Demographic data of the diabetic pilgrims admitted

\begin{tabular}{ll}
\hline Demographic data & n (\%) \\
\hline Gender & \\
Male & $40(50 \%)$ \\
Female & $40(50 \%)$ \\
Age (year) & \\
$<45$ & $2(2.5 \%)$ \\
$45-65$ & $48(60 \%)$ \\
$>65$ & $30(37.5 \%)$ \\
\hline
\end{tabular}

Overall participants 44 patients $(55 \%)$ had hypertension; 21 patients $(26.3 \%)$ had dyslipidemia.

The mean duration of diabetes was 9.37ans (Standard Deviation $+/-7.296)$.

Most of the diabetic had retinopathy 19 (23.8\%), followed by neuropathy $11(13.8 \%)$, nephropathy $9(11.3 \%)$ and heart diseases 1 $(1.3 \%)$.

32 patients $(40 \%)$ consulted for monitoring their blood glucose, noting that the most part of diabetic pilgrims did not take their glucometer with them and were unaware of the need of increased Self-Monitoring of Blood Glucose (SMBG) during times of illness or stress.

Our study showed that only $53(66.3 \%)$ patients were on regular dietary and hygienic measures while 27 patients (33.8\%) were irregular.

Distribution of diabetes medications taken by pilgrims is shown in Figure 2.

Four patients (5\%) presented diabetic ketoacidosis complication.

The mean of Random Plasma Glucose was $1.5855 \mathrm{~g} / \mathrm{l}$ (SD +/- 0.4)

The mean of HBA1c was $7.97 \%$ (SD +/- 1.392): HbA1c distribution of patients is shown in Figure 3.

Most of our patients were in blood pressure goals: Systolic BP $<$ $140 \mathrm{mmhg}$ for 71 patients $(88.8 \%)$ and Diastolic BP $<90 \mathrm{mmHg}$ for 75 patients $(93.8 \%)$.

The majority of patients $(80 \%)$ had not received appropriate advice and management of diabetes before travelling for Hajj.

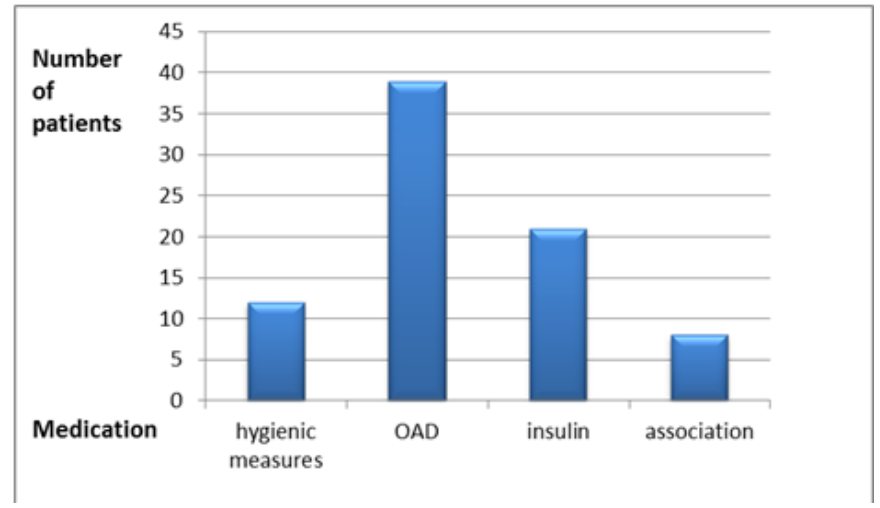

Figure 2 Diabetes medications taken by patients.

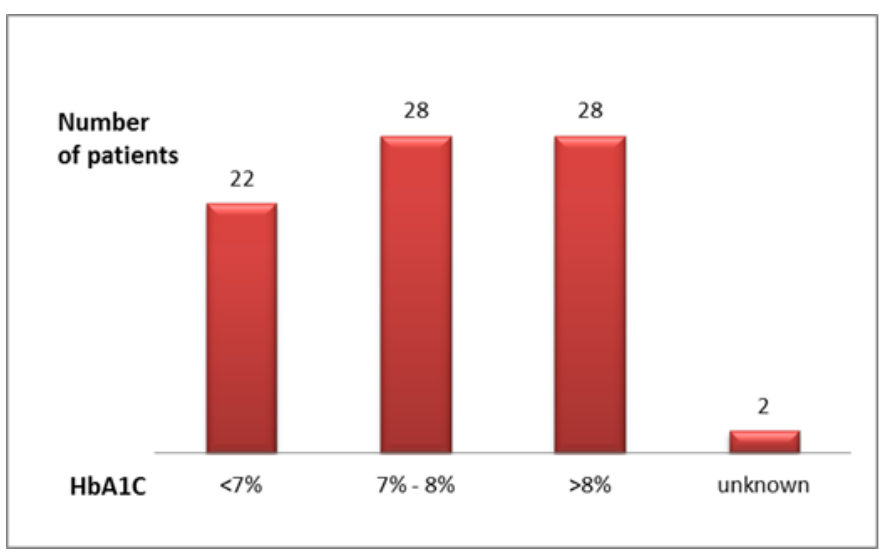

Figure $3 \mathrm{HbAlc}$ distribution of patients.

\section{Discussion}

Every year, the Kingdom of Saudi Arabia (KSA) hosts the Hajj pilgrimage, which is the largest mass gathering in the world held on a recurrent annual basis. ${ }^{3}$

A significant proportion of those performing Hajj is elderly and may suffer from chronic medical conditions. Considering the $10 \%$ prevalence of diabetes mellitus in this age group, about 250000 diabetic patients will participate in this crowded pilgrimage. ${ }^{4}$

The Hajj duties are very stressful for persons with chronic illnesses, especially the diabetics, in terms of physical activities and mental effort because a large number of people have to perform all rituals at specific periods of time in a limited space.,

During Hajj, the person's life routine changes, weather, diet and habits are different; therefore diabetes that depends on a stable routine would predictably be significantly affected. ${ }^{4}$

In our study, a total of $80(100 \%)$ patients belong to type $2 \mathrm{DM}$. This can be justified on the fact that almost all pilgrims were elderly and the prevalence of Type $2 \mathrm{DM}$ is much higher than Type $1 \mathrm{DM}$.

More than half of the patients were hypertensive, they must endeavor to control his blood pressure before travel and an attempt should be made to take into account the control during exercise. They should also be advised to either self-monitor their blood pressure regularly or adjust the antihypertensive dose accordingly. ${ }^{5}$

It was also interesting to note that the majority of Hajj pilgrims admitted did not receive any form of diabetic education. It was reflected in the low numbers of pilgrims who had adequate control 
over their blood sugar levels as evidenced by levels of HbA1c. Most diabetic pilgrims were unaware of the need of increased SMBG during times of illness or stress. ${ }^{7-8}$

During our study, we admitted 4 patients $(5 \%)$ for DKA that were hospitalized in emergency services in Almedina Al-Munawarah. In a prospective study of all diabetic ketoacidosis (DKA) admitted to a single hospital in Almedina Al-Munawarah, 18 episodes were examined. ${ }^{9}$

A unique study of the profile of 169 diabetic Omani pilgrims shows that eighty six per cent of the patients were on oral anti-hypoglycemic agents [OHA]. During the Hajj period, $2.4 \%$ of diabetic patients had a random plasma glucose $(\mathrm{RPG})<4.0 \mathrm{mmol} / \mathrm{L}, 14 \%$ had RPG $4.0-6.0$ $\mathrm{mmol} / \mathrm{L}$, and $49 \%$ were $>10.5 \mathrm{mmol} / \mathrm{L}$. The median age was 54 years [inter-quartile range 50-62y], and $28 \%$ had coronary heart disease, hypertension or both. ${ }^{10}$

In our study, $11.3 \%$ of patients had diabetic nephropathy and $1.3 \%$ had heart disease. Those patients must make effort to avoid dehydration and carry water bottles with them and as they should drink two or more liters daily, depending on the weather, thus avoiding any deterioration or renal function.

Many diabetic patients will have asymptomatic coronary artery disease so it is advisable to do an ECG in the pretravel consultation with clear instructions to present themselves to a health facility as soon as possible if chest pain, shortness of breath or palpitations arises.

Diabetic patients who had diabetic neuropathy (13.8\%) should avoid walking bare foot at all times because of risk to have foot injury. They can get a waiver to do some parts of Haj wearing protective shoes.

The prevention and management of threats to global health security and protecting the health and lives of pilgrims requires effective cooperation between numerous agencies within and outside the KSA. ${ }^{11}$

\section{Conclusion}

It is important to emphasize that healthcare professionals should be informed regarding characteristics of diabetic pilgrims.

Our study was limited to a relatively small patient population and the high prevalence of poorly controlled diabetes in our patient population.
Medical professionals should be aware of potential risks of Haij on diabetes, try to minimize the risk of complications and convince patients who are not fit to go to Mecca.

\section{Acknowledgments}

None.

\section{Conflict of interest}

The author declare there is no conflict of interest.

\section{References}

1. Hasan G, Moabber H, Alyamani A, et al. Study on risk factors (predisposing factors) for poor diabetes control during Hajj (1436/2015) in people with diabetes. Pak J Med Sci. 2016;32(5):1092-1096.

2. International Diabetes Federation. IDF Diabetes Atlas (Seventh Edition). 2015 .

3. Memish ZA, Zumla A, Alhakeem RF, et al. Hajj: infectious disease surveillance and control. Lancet. 2014;383(399934):2073-2082.

4. Mansour Siavash, Sepehr Haghighi. Recommendations for patients with diabetes mellitus during hajj pilgrimage. J Res Med Sci. 2012;17(10):988989.

5. Beshyah S, Sherif I. Care for People with Diabetes during The Moslem Pilgrimage (Haj) An Overview. Libyan J Med. 2008;3:39-41.

6. Al-Harthi AS, Al-Harbi M. Accidental injuries during muslim pilgrimage. Saudi Med J. 2001;22:523-525.

7. Standards of Medical Care in Diabetes. Diabetes Care. 2004;27(Suppl 1):S15-S35

8. Saudi Diabetes and Endocrine Association. Diabetes Management for a Healthy and Safe Hajj [Internet]. Saudi Diabetes \& Endocrine Association; 2013.

9. Yusuf M, Chaudhry S. Diabetic ketoacidosis in pilgrims visiting Madinah Al-Munawarah, Saudi Arabia. International Diabetes Digest. 1998;8:14 16

10. Baomer AA, el Bushra HE. Profile of diabetic Omani pilgrims to Mecca. East Afr Med J. 1998;75(4):211-214.

11. Shafi S, Dar O, Khan M, et al. The annual Hajj pilgrimage-minimizing the risk of ill health in pilgrims from Europe and opportunity for driving the best prevention and health promotion guidelines. Int $J$ Infect Dis. 2016;47:79-82. 